\title{
Intracranial Serpentine Aneurysms: Spontaneous Changes of Angiographic Filling Pattern
}

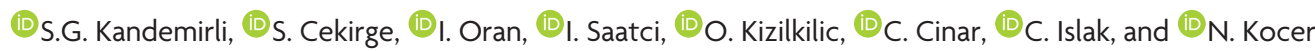

\begin{abstract}
BACKGROUND AND PURPOSE: Serpentine aneurysms are partially thrombosed aneurysms with an eccentrically located tortuous intraaneurysmal vascular channel. The large size, distinctive neck anatomy, and supply of the brain parenchyma by the outflow tract pose technical challenges in treatment. The aim of this study was to discuss the endovascular treatment results and illustrate the dynamic nature of serpentine aneurysms. Spontaneous transformation of saccular and fusiform aneurysms into serpentine morphology, along with a case of serpentine-into-fusiform aneurysm transformation during follow-up, is presented.
\end{abstract}

MATERIALS AND METHODS: A retrospective analysis from 3 institutions revealed 15 patients with serpentine aneurysms who underwent diagnostic evaluation and endovascular treatment. Nine of the 15 patients underwent endovascular occlusion of the parent vessel with detachable balloon or coils. Six of the 15 patients underwent aneurysm and parent artery occlusion with coiling.

RESULTS: In 11 patients, improvement or resolution of symptoms was achieved by an endovascular approach without any treatmentrelated morbidity. Morbidity related to treatment in the immediate postoperative period was seen in 3 patients, with resolution of the deficits at long-term follow-up in 2 patients and persistence of a mild deficit in 1 patient. Endovascular treatment failed to achieve resolution of symptoms in a case with a basilar tip aneurysm treated by aneurysm coiling.

CONCLUSIONS: Serpentine aneurysms are dynamic structures with spontaneous transformation possible from a saccular or fusiform shape into a serpentine configuration. An endovascular approach by parent vessel occlusion or intra-aneurysmal occlusion is a successful treatment technique for serpentine aneurysms.

ABBREVIATIONS: $\mathrm{ACA}=$ anterior cerebral artery; $\mathrm{BTO}=$ balloon test occlusion; $\mathrm{ECA}=$ external carotid artery; $\mathrm{PAO}=$ parent artery occlusion; $\mathrm{PCA}=$ posterior cerebral artery

$\mathbf{S}_{\mathrm{an} \cos }^{\mathrm{en}}$ erpentine aneurysms constitute a rare form of intracranial aneurysms with unique radiologic and pathologic features. ${ }^{1,2}$ Serpentine aneurysms are partially thrombosed aneurysms and contain an eccentrically located tortuous intra-aneurysmal vascular channel. ${ }^{3,4}$ The main distinctive features are the presence of separate inflow and outflow tracts and supply of the brain parenchyma by the outflow tract. ${ }^{4,5}$ The pathogenesis of serpentine aneurysms is not clear, and several hypotheses have been pro-

Received April 9, 2018; accepted after revision June 12

From the Division of Neuroradiology (S.G.K., O.K., C.I., N.K.), Department of Radiology, Cerrahpasa Medical Faculty, Istanbul University, Istanbul, Turkey; Interventional Neuroradiology Department (S.C.), Koru and Bayındır Hospital, Ankara, Turkey; Division of Neuroradiology (I.O., C.C.), Department of Radiology, Ege University Medical Faculty, Izmir, Turkey; and Interventional Neuroradiology Department (S.C., I.S.), Yuksek Ihtisas University, Koru Hospital, Ankara, Turkey.

Please address correspondence to Naci Kocer, MD, Department of Radiology, Division of Neuroradiology, Cerrahpasa Medical Faculty, Istanbul University, Kocamustafapasa/Istanbul 34098, Turkey; e-mail: nkocer@istanbul.edu.tr

三 Indicates article with supplemental on-line tables.

http://dx.doi.org/10.3174/ajnr.A5746 posed to explain the evolutionary features. ${ }^{6-8}$ The most widely accepted mechanism is continued expansion of a saccular aneurysm into a serpentine configuration termed the "Coanda effect." ${ }^{\prime 6}$ The common entity in the pathophysiology of serpentine aneurysms is the dynamic nature of thrombosis and aneurysm formation. ${ }^{4}$

The large size, distinctive neck anatomy, and supply of the brain parenchyma by the outflow tract pose technical challenges in treatment. ${ }^{4}$ In the initial reports, surgical obliteration alone was the mainstay treatment; however, surgical external carotid artery (ECA)-ICA anastomosis and an endovascular approach have expanded the treatment options. ${ }^{4,8}$

This study focused on the clinical and imaging findings of 15 patients with serpentine aneurysms treated by endovascular routes. We present cases of saccular and fusiform aneurysms evolving into serpentine aneurysms during follow-up to illustrate the possible formation mechanisms of serpentine aneurysms. Additionally, a case of spontaneous transformation of a serpentine aneurysm into a fusiform aneurysm is presented that has not been 
reported in the literature previously. These cases illustrate the dynamic nature of the mechanisms involved in serpentine aneurysm pathogenesis.

\section{MATERIALS AND METHODS}

A retrospective analysis of the medical records from 3 institutions revealed 21 patients with serpentine aneurysms who had endovascular or surgical treatment. Fifteen patients who underwent endovascular treatment constituted the study group. Patients with surgical intervention alone were not included in this study.

All patients underwent selective cerebral angiography in addition to a CT scan and/or MR imaging. At the time of diagnosis, 5 of the 15 patients had not received treatment initially. However, 4 of them were subsequently treated with an endovascular route due to worsening of symptoms at follow-up.

The age range was $17-70$ years (mean, 40.2 years) with a maleto-female ratio of 1.14. The main presenting features were headache, neurologic deficits secondary to mass effect, or distal emboli (On-line Table 1). The neurologic deficits included hemiparesis, sensory symptoms, cranial nerve involvement, and brain stem compression symptoms. One patient initially presenting with headache refused treatment and later presented with rupture of the aneurysm.

Ten aneurysms involved the anterior circulation (7 at the MCA, 2 at the ICA, and 1 at the anterior cerebral artery [ACA]), whereas 5 aneurysms involved the posterior circulation ( 1 basilar artery, 4 posterior cerebral arteries [PCAs]) (On-line Table 1). Mean aneurysm size was $4.9 \mathrm{~cm}$, with a minimum size of $2.5 \mathrm{~cm}$ and maximum size of $8 \mathrm{~cm}$.

Nine of the 15 patients underwent endovascular occlusion of the parent vessel with detachable balloons (2 patients) and detachable coils (7 patients). Six of the 15 patients underwent aneurysm and parent artery occlusion with coiling (in 2 of them, Onyx [Covidien, Irvine, California] was used as an adjunctive embolic material). In a single case, bypass surgery was performed before endovascular aneurysm occlusion.

Systemic anticoagulation during endovascular treatment was achieved by bolus infusion of 5000 IU of heparin after insertion of a femoral sheath. The bolus infusion of heparin was followed by a continuous drip (1000-1500 IU/h) to double the baseline activated clotting time.

Balloon test occlusion (BTO) before endovascular treatment was performed for 5 of 15 patients (a single cavernous ICA aneurysm and 4 proximal MCA aneurysms). During BTO, collateral filling of the occluded side through the circle of Willis or via other collaterals (such as pial-pial) and the transit time to the venous phase (which should demonstrate a $<2$-second difference compared with nonoccluded regions) were evaluated. While BTO showed adequate collateral flow in 4 patients (cases 2, 3, 8, and 9), there was inadequate flow in 1 patient (case 11) in whom intracranial bypass surgery was performed before the endovascular parent artery occlusion. Test occlusion before endovascular treatment was not performed for distally located aneurysms (4 PCA, 3 MCA M2-M3, 1 ACA, and 1 basilar tip aneurysm). Additionally, BTO could not be performed due to technical difficulty in a case with a supraclinoid ICA aneurysm.

\section{RESULTS}

In 11 patients, improvement or resolution of symptoms was achieved by an endovascular approach without any treatmentrelated morbidity.

New MR imaging positive for ischemic complications was seen in 3 patients (cases 3,11, and 14). Deficits totally resolved in 2 cases, whereas 1 case had a mild deficit at follow-up. No clinically silent new ischemic region in the postoperative period was observed in the remaining 12 patients. Additionally, no hemorrhagic findings complicated the postoperative course.

Case 11 had a left MCA inferior trunk aneurysm and presented with multiple transient ischemic attacks before treatment. In this patient, BTO showed inadequate collateral supply, and intracranial bypass was performed before aneurysm occlusion. This patient still had a slight right hemiparesis and facial paresis in the immediate postoperative period with resolution of deficits at the 3-month follow-up. Case 14 had a left PCA aneurysm treated by parent artery occlusion (PAO). BTO was not performed in this case. Right hemihypesthesia and right thalamic hand syndrome developed in the immediate postembolization period with total resolution at the 1-year follow-up.

Case 3 with a left MCA (M1-M2 segments) aneurysm had adequate collateral supply during BTO occlusion. Following intra-aneurysmal coiling and PAO, the patient had new-onset dysphasia and right hemiparesis. During follow-up, deficits partially ameliorated, the patient presented with intense headache at the 2-month follow-up. MR imaging revealed abscess formation along with extensive edema around the aneurysm sac. The patient underwent total resection of the abscess cavity and aneurysm. On the postoperative course, the patient had persistence of mild dysphasia with total resolution of right hemiparesis.

Endovascular treatment failed to achieve resolution of symptoms in a case (case 5) with a basilar tip aneurysm treated by aneurysm coiling. There was a substantial increase in brain stem compression with worsening of symptoms at the 6-month follow-up.

At follow-up (mean duration of 27 months), no recanalization of the aneurysm sac was observed. In a single case (case 5), there was an increase in brain stem compression at the 6-month followup. Perianeurysmal edema regressed in all other cases; additionally, aneurysm mass size decreased in 8 cases.

Among the 15 aneurysms, 12 patients presented with serpentine morphology; 3 of 15 aneurysms (cases 1, 3, and 8) did not have a serpentine morphology initially and changed into a serpentine configuration spontaneously during follow-up. Aneurysms in case 8 had a saccular shape, and cases 1, 3 had a fusiform shape initially. In a single case, spontaneous transformation of a serpentine aneurysm into a fusiform aneurysm was seen at the 2-year follow-up (case 2).

Herein, we describe these cases in detail to illustrate the different formation mechanisms of serpentine aneurysms.

\section{Spontaneous Transformation of a Saccular Aneurysm into a Serpentine Aneurysm (Case 8)}

A 37-year-old woman presented with severe headache (Fig 1). Diagnostic imaging revealed a saccular aneurysm at the left MCA bifurcation. Per the patient's preference, she did not undergo treatment at the initial presentation. Five years later, the patient 


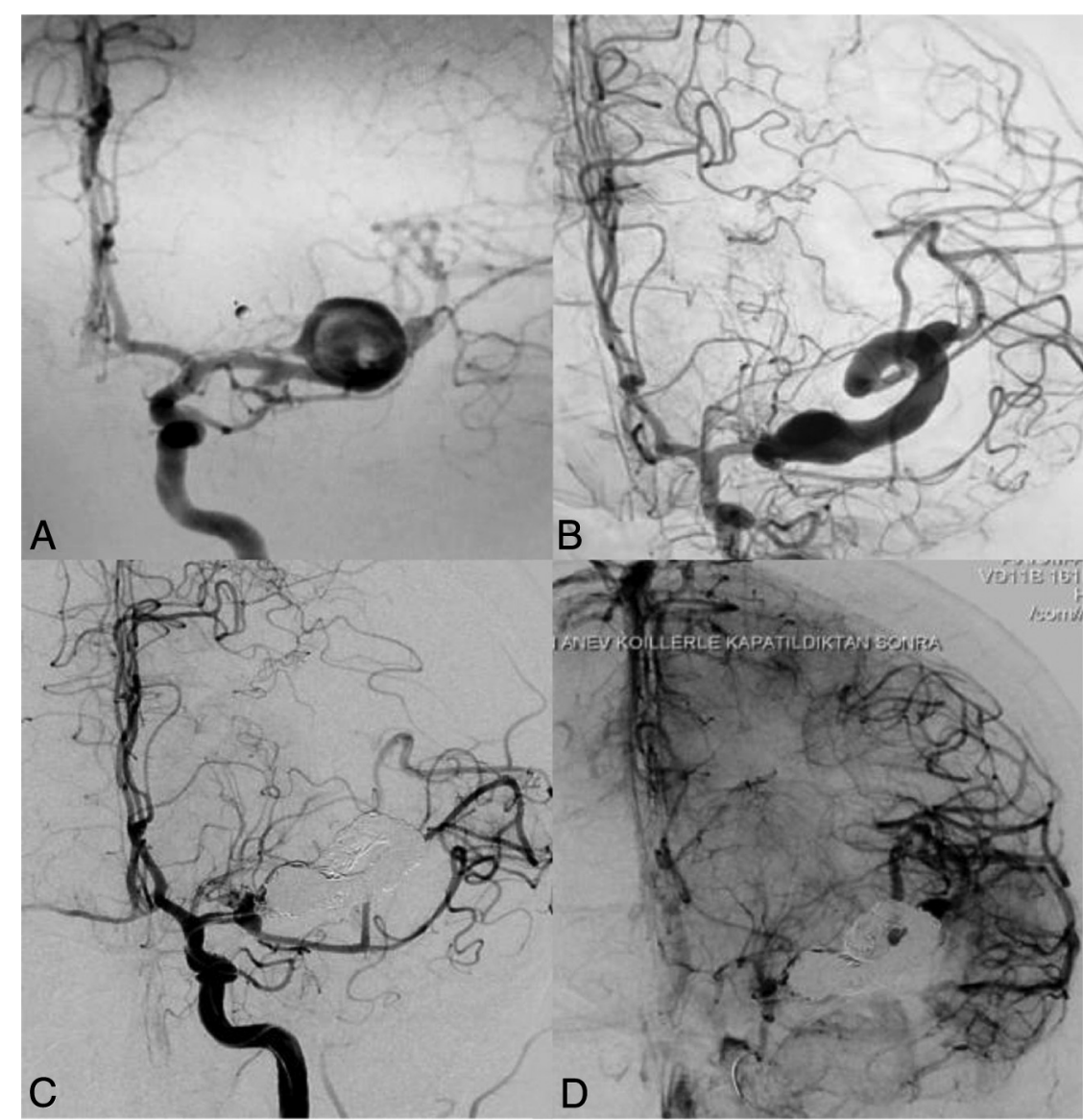

FIG 1. A 37-year-old woman who presented with severe headache. A, Left ICA angiography shows a saccular aneurysm $(1.44 \times 1.65 \mathrm{~cm})$ at the left MCA bifurcation. $B$, Repeat angiography 5 years later reveals marked enlargement of the aneurysm $(5 \times 4 \times 4 \mathrm{~cm})$ with incorporation of the upper MCA trunk into the serpentine aneurysm lumen. $C$ and $D$, Endovascular occlusion of the serpentine aneurysm and the parent artery by coiling and Onyx injection was performed.

The patient was treated by parent vessel occlusion of the PCA with detachable coils. The distal PCA branches were opacified by pial-pial collaterals through the MCA. At 1-year follow-up, the patient was neurologically intact with resolution of symptoms. DSA at 1 year showed exclusion of the aneurysm lumen from circulation and stable perfusion of the distal PCA territory with a thrombosed mass.

Case 3 was a fusiform aneurysm of the left MCA (M1-M2 segments) in a 39-year-old female patient who presented with headache. The patient presented with worsening of symptoms 1 year later, when DSA revealed marked enlargement of the fusiform aneurysm. Endovascular treatment was contemplated. Six days later, during endovascular treatment, the aneurysm acquired a doughnut shape with partial intra-aneurysmal thrombosis. Intraaneurysmal coiling was performed. In the immediate postoperative period, the patient had dysphasia and right hemiparesis. The postoperative course was further complicated by abscess formation adjacent to the coiled aneurysm, which required surgical drainage and resection of the abscess cavity. At the 6-month follow-up, the patient had mild dysphasia with resolution of right hemiparesis.

presented with worsening of symptoms. On DSA, marked enlargement of the aneurysm with a change into a serpentine configuration was noted. The patient tolerated a balloon test occlusion, and the lumen of the serpentine aneurysm was occluded by coiling and Onyx injection. At 1-year follow-up, the patient was neurologically intact with resolution of the perianeurysmal edema and absence of flow in the aneurysm.

\section{Spontaneous Transformation of a Fusiform Aneurysm into a Serpentine Aneurysm (Cases 1 and 3)}

At the initial presentation, 2 cases with fusiform aneurysms were managed conservatively (Figs 2 and 3 ). These cases presented with worsening of symptoms at the long-term follow-up (1 and 6 years), at which time the diagnostic examinations revealed enlargement of the aneurysms and evolution of fusiform aneurysms into serpentine aneurysms.

In case 1, a 32-year-old man presented with headache and diaphoresis. Cerebral angiography at the time of initial evaluation showed fusiform enlargement of the right PCA. No treatment was performed initially. Six years later, the patient presented with worsening of symptoms, and diagnostic imaging revealed marked enlargement of the aneurysm along with edema. The initially fusiform aneurysm had transformed into a serpentine configuration.

\section{Spontaneous Transformation of a Serpentine Aneurysm into a Fusiform Aneurysm (Case 2)}

A 39-year-old woman presented with headache and diplopia; cerebral DSA revealed a giant serpentine aneurysm in the cavernous segment of the right ICA (Fig 4). No treatment was contemplated at the time of initial evaluation. At 2-year follow-up, DSA revealed transformation of the serpentine aneurysm into a fusiform aneurysm with no change in patient symptoms. The patient opted for treatment and was treated by PAO using a detachable balloon. Postoperatively, the patient had no neurologic deficit.

\section{DISCUSSION}

In our review of the literature, there were 101 giant serpentine aneurysms (On-line Table 2). Serpentine aneurysms were seen more commonly in young males, with a male-to-female ratio of 1.86 at an average age of 35.6 years (range, $4-71$ years) (On-line Table 2). Seventy aneurysms (69.3\%) involved the anterior circulation, where 48 aneurysms (47.5\%) were in the MCA territory, 18 aneurysms (12.9\%) were within the ICA, and 9 aneurysms (8.9\%) were within the ACA. Thirty-one aneurysms (30.7\%) involved the posterior circulation, where 17 aneurysms $(16.8 \%)$ were in the PCA and 14 aneurysms (13.9\%) involved the vertebral artery, 


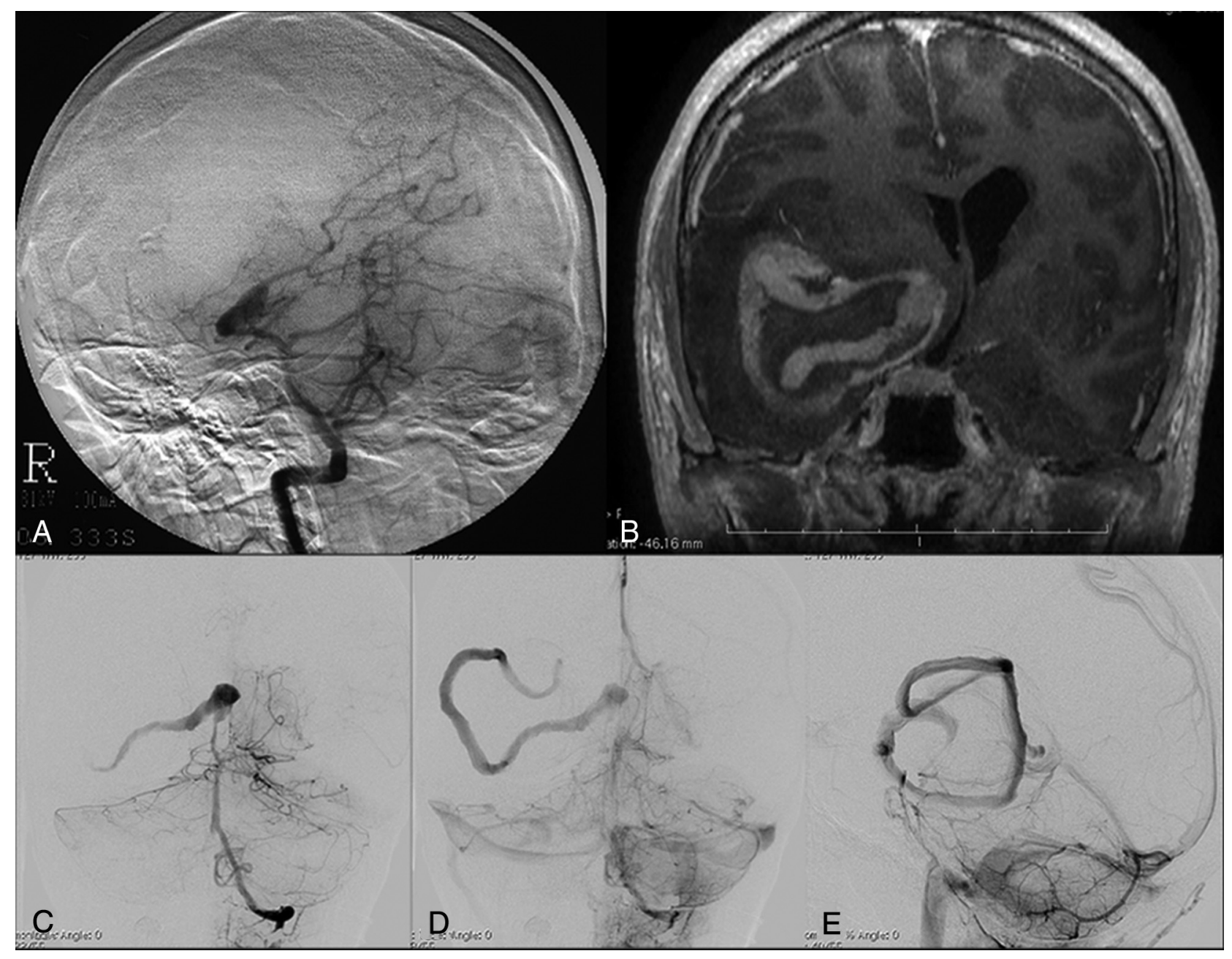

FIG 2. A 32-year-old man who presented with headache and diaphoresis. A, Cerebral angiography shows fusiform enlargement of the right PCA (P2 and P3 segments). B, Six years later, postcontrast MR imaging reveals an enhancing vascular channel on the postgadolinium T1-weighted image surrounded by nonenhancing thrombus. Note the associated mass effect and midline shift. $C-E$, Cerebral angiography demonstrates marked enlargement of the aneurysm with a tortuous vascular channel.

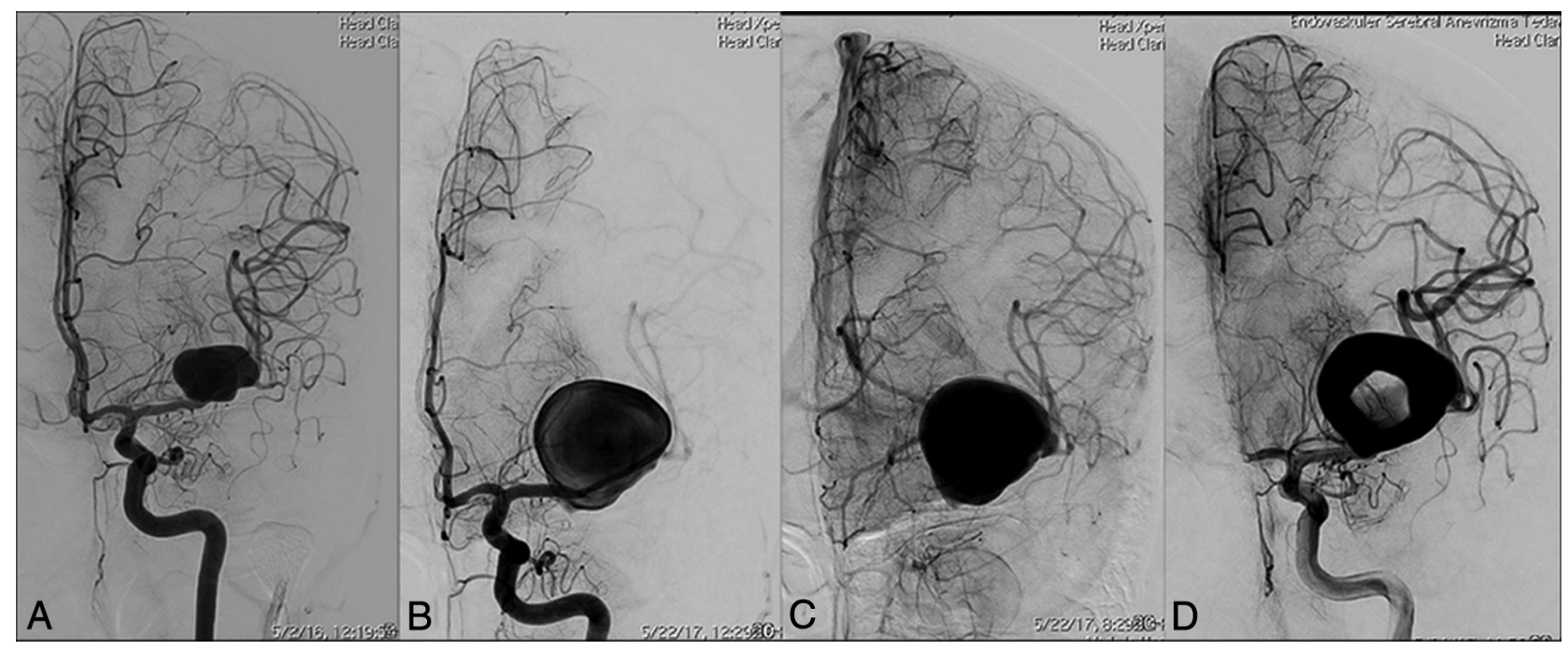

FIG 3. A 39-year-old woman who presented with headache. A, Cerebral angiography shows a fusiform aneurysm involving the left MCA Ml and M2 segments. $B$ and C, DSA 1 year later demonstrates marked enlargement of the fusiform aneurysm with sluggish intra-aneurysmal blood flow. $D$, Six days later, angiography before endovascular treatment reveals partial intra-aneurysmal thrombosis with the classic doughnut shape evident. 


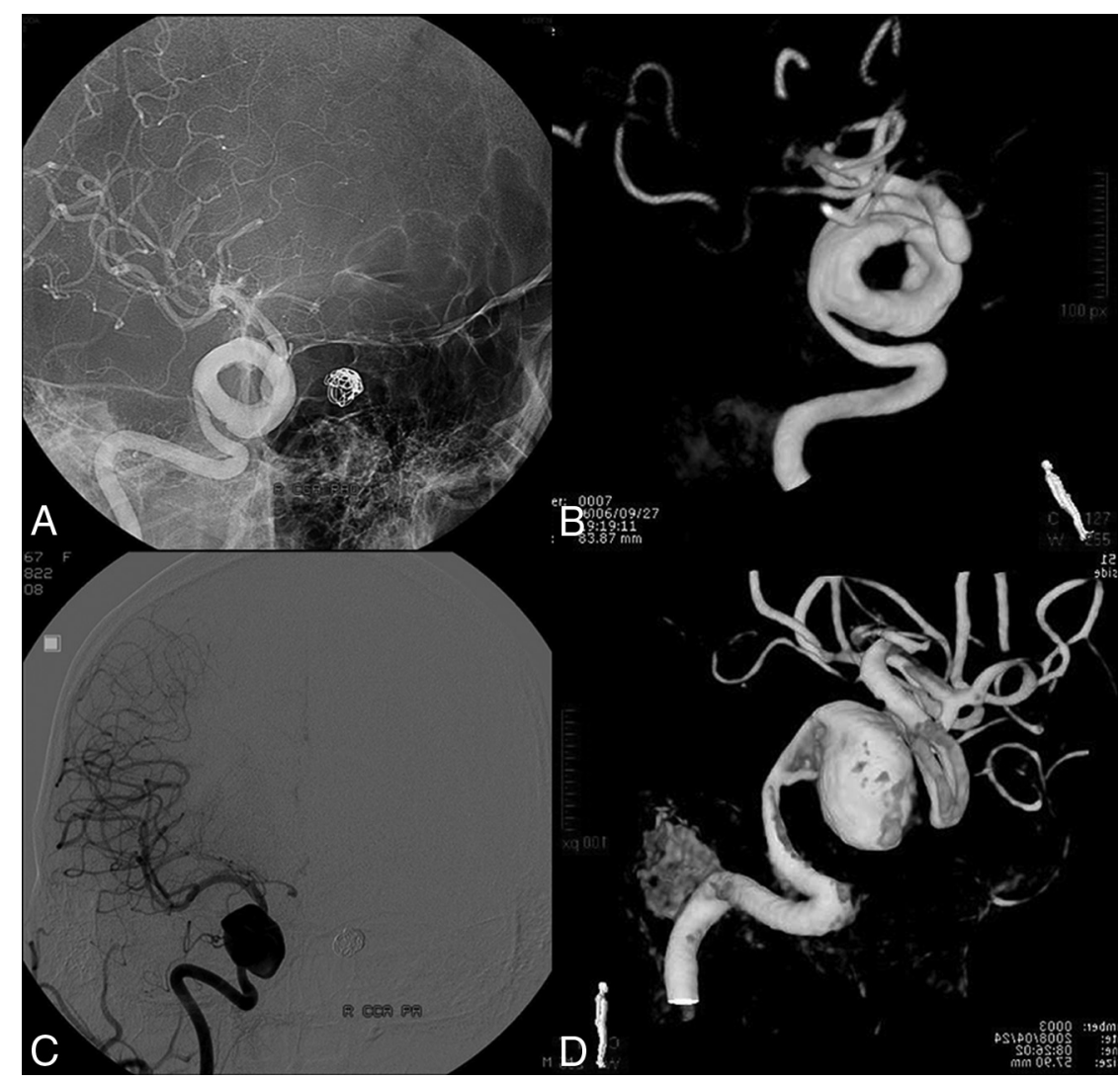

FIG 4. A 39-year-old woman who presented with headache and diplopia. $A$ and $B$, Initial cerebral angiography shows a giant serpentine aneurysm in the cavernous segment of the right ICA. $C$ and $D$, Repeat angiogram at the 2-year follow-up demonstrates that the aneurysm has lost its serpentine formation and acquired a fusiform morphology.

vertebrobasilar junction, basilar artery, posterior communicating artery, PICA, or superior cerebellar artery (On-line Table 2). The main presenting feature was symptoms related to mass effect, in which distinct symptomatology was based on the location of the aneurysm. ${ }^{4,5,8-10}$ Although it is generally accepted that serpentine aneurysms are protected against rupture by the thick fibrous wall, Suzuki et al ${ }^{11}$ reported a $28 \%$ rate of subarachnoid hemorrhage in 39 serpentine aneurysms. Another cause of morbidity and mortality is related to ischemic stroke in the territory supplied by the serpentine aneurysm. ${ }^{12}$ In our series, up to treatment time, 2 patients had distal emboli, whereas a case of rupture was seen in a single patient who initially presented with headache and refused treatment and later presented with SAH.

The pathologic examinations of serpentine aneurysms have shown tortuous vascular channels within old organized thrombus containing revascularization..$^{3,6,13-16}$ The walls of the aneurysms are composed primarily of acellular, fibrous tissue and lack an internal elastic lamina or endothelial layer. ${ }^{3,4}$ Additionally, arterial vessels similar to the vasa vasorum that course through the adventitial layer of the aneurysm have been described. ${ }^{4,6}$

In conservative management of serpentine aneurysms, there is a high rate of neurologic deterioration and death. ${ }^{11}$ The aim of treatment is to decrease the mass effect while maintaining adequate distal circulation. A variety of surgical techniques has been used in the treatment of serpentine aneurysms. Visualization of perforating vessels and separation from the parent vessel, brain retraction required for proximal control, and the rich peripheral vascular supply of the aneurysm could cause challenges and marked blood loss during an operation. ${ }^{4,5}$ Additionally, the outflow channel of the aneurysm supplies the normal brain parenchyma. If there is inadequate collateral supply of the brain parenchyma, revascularization procedures (like ECA-ICA bypass) may be needed before aneurysm occlusion. ${ }^{17-19}$ We assessed collateral flow by BTO in certain aneurysms; no Wada testing was performed in this study group. We have not performed BTO in certain regions like the PCA or distal MCA territory because there is a risk of endothelial damage with possible retrograde thrombosis. ${ }^{1}$ Especially for the PCA supply region, which has a rich collateral supply from the ACA and MCA, a low incidence of visual field deficits complicating parent artery occlusion has been reported. ${ }^{10}$

An endovascular approach by parent vessel occlusion using coils or detachable balloons has been successfully used in cases with an established adequate distal collateral supply., ${ }^{5,9,20}$ Aneurysm occlusion by trapping or proximal occlusion using coils or glue has been reported. ${ }^{2,21}$ In our series, 11 patients (73.3\%) achieved improvement or resolution of symptoms following therapy without treatment-related morbidity, whereas 3 cases $(20 \%)$ had distal infarction, with total resolution of symptoms in 2 of these patients.

The pathogenesis of serpentine aneurysms is not clear. Unlike saccular aneurysms, serpentine aneurysms do not have a predilection for arterial branch points, indicating a different pathophysiology compared with saccular aneurysms. ${ }^{3}$ The most accepted hypothesis is the Coanda effect proposed by Fodstad et al. ${ }^{6}$ In their initial report, Fodstad et al treated a giant intracavernous aneurysm by carotid artery ligation. Following ligation, partial thrombi formed in the aneurysm with incomplete occlusion of the aneurysm. Six months later, the incompletely occluded aneurysm evolved into a giant serpentine aneurysm. This transformation of a saccular aneurysm into a serpentine aneurysm can be explained by continuing blood flow into a large incompletely occluded aneurysm. This mechanism is termed as the Coanda effect, in which the jet flow of blood is directed and reinforced toward one wall instead of the central portion of the aneurysm. ${ }^{15}$ Subsequently, blood flow in the central portion of the aneurysm and adjacent arterial wall is markedly decreased, with predisposition to stagnant blood flow and thrombus formation. Because of thrombus formation, the aneurysm enlarges and evolves into a serpentine configuration. The Coanda effect also explains the 
higher predilection of serpentine aneurysms in the MCA territory compared with the ICA. The higher jet force of the blood flow prevents stagnation of blood in the ICA, whereas the jet force of blood flow is lower in the MCA with predisposition to stagnation and thrombus formation. Another reason for higher MCA predilection is the absence of dural or osseous structures to limit expansion of the aneurysm in the MCA territory. ${ }^{6,22}$

In the literature, there are also cases reporting spontaneous evolution of fusiform aneurysms into giant serpentine aneurysms. ${ }^{1,7,23,24}$ Initially, Tomasello et $\mathrm{al}^{23}$ described a case of a small MCA fusiform aneurysm that progressed to a serpentine aneurysm during 5 years. In a similar case, Senbokuya et $\mathrm{al}^{7}$ reported a case of a distal ACA aneurysm that evolved into a serpentine aneurysm after 5 months. In our series, there were 2 cases of spontaneous transformation of fusiform aneurysms into serpentine aneurysms during 6 days to 6 years. In case 3, a fusiform aneurysm was transformed into a serpentine aneurysm 6 days later, following diagnostic angiography. Six days later, thrombosis within the aneurysm and a doughnut-like configuration were noted. This phenomenon of angiography inducing thrombosis in a giant aneurysm has also been reported in the literature. ${ }^{25}$ In this case, the authors proposed that thrombosis might be related to the internal thrombosis initiated by the contrast agent used in angiography. ${ }^{25}$ Arterial dissection may also be the initial event in the development of serpentine aneurysms; Verny et $\mathrm{al}^{26}$ reported a case of an MCA dissecting aneurysm that evolved into a serpentine aneurysm during 11 years.

Spontaneous complete occlusion of a giant saccular aneurysm is a well-recognized phenomenon that can occur in $13 \%-20 \%$ of cases; however, spontaneous thrombosis in serpentine aneurysms is rarely reported, with 3 cases available in the literature. ${ }^{5,25,27}$ The first case was reported by Aletich et $\mathrm{al},{ }^{5}$ in which an MCA serpentine aneurysm was spontaneously thrombosed with persistent thrombosis documented at the 1-year follow-up. Similarly, Sari et $\mathrm{al}^{25}$ have reported a case of spontaneous and complete thrombosis of a serpentine aneurysm with persistent thrombosis documented at the 3-year follow-up. Spontaneous occlusion of a serpentine aneurysm can be related to slow blood flow and thrombus formation. ${ }^{28}$ Endothelial damage related to turbulent blood flow may also be an important factor in thrombus formation. However, even complete thrombosis of a serpentine aneurysm should not be considered stable because Lee et $\mathrm{al}^{29}$ reported recanalization of a completely thrombosed serpentine aneurysm. The exact mechanism of recanalization is not clear; however, thrombus liquefaction and subsequent intrathrombotic dissection by blood flow might be involved. In addition to spontaneous thrombosis, as demonstrated in our series, spontaneous transformation of serpentine aneurysms into fusiform aneurysms may occur. This reflects the dynamic nature of intra-aneurysmal thrombosis that can spontaneously recanalize.

\section{CONCLUSIONS}

Serpentine aneurysms are partially thrombosed aneurysms with a patent, tortuous vascular lumen coursing through the aneurysm. We presented cases of spontaneous evolution of saccular and fusiform aneurysms into serpentine aneurysms during follow-up. Additionally, a case of spontaneous transformation of a serpen- tine aneurysm into a fusiform aneurysm is presented, indicating the dynamic nature of thrombosis involved in serpentine aneurysm pathogenesis.

Disclosures: Saruhan Cekirge-UNRELATED: Consulting Fee or Honorarium: Medtronic, MicroVention; Stock/Stock Options: eLUM Technologies, NDI Inc. Isil Saatci-UNRELATED: Consultancy: Medtronic, MicroVention. Civan Islak—UNRELATED: Patents (Planned, Pending or Issued): floating diameter embolic coil US 2015/ 0327868; Stock/Stock Options: Neuro Device Innovations Inc, Comments: 10\% shareholder. Naci Kocer-UNRELATED: Consultancy: MicroVention; Payment for Lectures Including Service on Speakers Bureaus: MicroVention; Travel/Accommodations/Meeting Expenses Unrelated to Activities Listed: MicroVention.

\section{REFERENCES}

1. Coley SC, Hodgson TJ, Jakubowski J. Coil embolization of giant serpentine aneurysms: report of two cases arising from the posterior cerebral artery. Br J Neurosurg 2002;16:43-47 CrossRef Medline

2. van Rooij WJ, Sluzewski M, Beute GN. Endovascular treatment of giant serpentine aneurysms. AJNR Am J Neuroradiol 2008;29: 1418-19 CrossRef Medline

3. Segal HD, McLaurin RL. Giant serpentine aneurysm: report of two cases. J Neurosurg 1977;46:115-20 CrossRef Medline

4. Christiano LD, Gupta G, Prestigiacomo CJ, et al. Giant serpentine aneurysms. Neurosurg Focus 2009;26:E5 CrossRef Medline

5. Aletich VA, Debrun GM, Monsein LH, et al. Giant serpentine aneurysms: a review and presentation of five cases. AJNR Am JNeuroradiol 1995;16:1061-72 Medline

6. Fodstad H, Liliequist B, Wirell S, et al. Giant serpentine intracranial aneurysm after carotid ligation: case report. J Neurosurg 1978;49: 903-09 CrossRef Medline

7. Senbokuya N, Kanemaru K, Kinouchi H, et al. Giant serpentine aneurysm of the distal anterior cerebral artery. J Stroke Cerebrovasc Dis 2012;21:910.e917-11 CrossRef Medline

8. Xu K, Yu T, Guo Y, et al. Study and therapeutic progress on intracranial serpentine aneurysms. In J Med Sci 2016;13:432-39 CrossRef Medline

9. Mawad ME, Klucznik RP. Giant serpentine aneurysms: radiographic features and endovascular treatment. AJNR Am J Neuroradiol 1995;16:1053-60 Medline

10. Xianli L, Youxiang L, Liu A, et al. Endovascular treatment of intracranial giant serpentine aneurysms. Neuroradiol J 2007;20:237-41 CrossRef Medline

11. Suzuki S, Takahashi T, Ohkuma H, et al. Management of giant serpentine aneurysms of the middle cerebral artery: review of literature and report of a case successfully treated by STA-MCA anastomosis only. Acta Neurochir (Wien) 1992;117:23-29 CrossRef Medline

12. Mahadevan A, Tagore R, Siddappa NB, et al. Giant serpentine aneurysm of vertebrobasilar artery mimicking dolichoectasia: an unusual complication of pediatric AIDS - report of a case with review of the literature. Clin Neuropathol 2008;27:37-52 CrossRef Medline

13. Sadik AR, Budzilovich GN, Shulman K. Giant aneurysm of middle cerebral artery: a case report. J Neurosurg 1965;22:177-81 CrossRef Medline

14. Terao H, Muraoka I. Giant aneurysm of the middle cerebral artery containing an important blood channel: case report. J Neurosurg 1972;37:352-56 CrossRef Medline

15. Cantu RC, LeMay M. A large middle cerebral aneurysm presenting as a bizarre vascular malformation. $\mathrm{Br}$ J Radiol 1966;39:317-19 CrossRef

16. Belec L, Cesaro P, Brugieres P, et al. Tumor-simulating giant serpentine aneurysm of the posterior cerebral artery. Surg Neurol 1988;29: 210-15 CrossRef Medline

17. Amin-Hanjani S, Chen PR, Chang SW, et al. Long-term follow-up of giant serpentine MCA aneurysm treated with EC-IC bypass and proximal occlusion. Acta Neurochir (Wien) 2006;148:227-28 CrossRef Medline

18. Isla A, Alvarez F, Roda JM, et al. Serpentine aneurysm: regrowth after a superficial temporal artery-middle cerebral artery bypass

AJNR Am J Neuroradiol 39:1662-68 Sep 2018 www.ajnr.org

1667 
and internal carotid artery ligation: case report. Neurosurgery 1994; 34:1072-74 Medline

19. Greene KA, Anson JA, Spetzler RF. Giant serpentine middle cerebral artery aneurysm treated by extracranial-intracranial bypass: case report. J Neurosurg 1993;78:974-78 CrossRef Medline

20. Fanning NF, Kelleher MO, Ryder DQ. The pretzel sign: angiographic pattern of tortuous intra-aneurysmal blood flow in a giant serpentine aneurysm. Br J Neurosurg 2003;17:67-71 Medline

21. Otsuka G, Miyachi S, Handa T, et al. Endovascular trapping of giant serpentine aneurysms by using Guglielmi detachable coils: successful reduction of mass effect: report of two cases. J Neurosurg 2001; 94:836-40 CrossRef Medline

22. Kumabe T, Kaneko U, Ishibashi T, et al. Two cases of giant serpentine aneurysm. Neurosurgery 1990;26:1027-32; discussion 1032-33 CrossRef Medline

23. Tomasello F, Albanese V, Cioffi FA. Giant serpentine aneurysms: a separate entity. Surg Neurol 1979;12:429-32 Medline
24. Anson JA, Lawton MT, Spetzler RF. Characteristics and surgical treatment of dolichoectatic and fusiform aneurysms. J Neurosurg 1996;84:185-93 CrossRef Medline

25. Sari A, Kandemir S, Kuzeyli K, et al. Giant serpentine aneurysm with acute spontaneous complete thrombosis. AJNR Am J Neuroradiol 2006;27:766-68 Medline

26. Verny C, Marc G, Pasco A, et al. Middle cerebral artery dissection gives rise to giant serpentine aneurysm. Cerebrovasc Dis 2008;25: 283-85 CrossRef Medline

27. McLaughlin N, Denis D, Bojanowski MW. Neoangiogenesis of a serpentine middle cerebral artery aneurysm. Acta Neurochir (Wien) 2012;154:63-64 CrossRef Medline

28. Pany A, Sobri M, Valarmathi S, et al. Giant serpentine middle cerebral artery aneurysm. Med J Malaysia 2004;59:422-24 Medline

29. Lee KC, Joo JY, Lee KS, et al. Recanalization of completely thrombosed giant aneurysm: case report. Surg Neurol 1999;51:94-98 CrossRef Medline 